\title{
eDNA detection of corallivorous seastar (Acanthaster $c f$. solaris) outbreaks on the Great Barrier Reef using digital droplet PCR
}

\author{
Sven Uthicke ${ }^{1} \mathbb{C} \cdot$ Miles Lamare $^{2} \cdot$ Jason R. Doyle $^{1}$
}

Received: 4 July 2018 / Accepted: 6 September 2018/Published online: 12 September 2018

(C) The Author(s) 2018

\begin{abstract}
Coral loss through consumption by corallivorous crown-of-thorns seastars (CoTS, Acanthaster spp.) is a major contributor to the coral reef crisis in the Indo-Pacific region. The fourth wave of Acanthaster cf. solaris outbreaks since the 1960s started around 2010 on Australia's Great Barrier Reef. Ecological monitoring failed to detect early outbreak stages, thus preventing timely intervention. Here, we develop a digital droplet PCR (ddPCR)-based method to detect environmental DNA (eDNA) of CoTS in 2-1 water samples that can be compared with abundances of the species recorded by divers along $200-\mathrm{m}^{2}$ transects. Aquarium tests demonstrated that eDNA was readily detectable and increases proportional to the biomass of CoTS $\left(R^{2}=0.99, p<0.0001\right)$. Adaptation from a quantitative PCR technique developed for CoTS larvae (Doyle et al. in Marine Biology 164:176, 2017) to ddPCR improved the limit of quantification (LOQ) by a factor of 45. During field verification on 11 reefs, CoTS eDNA was detectable on all reefs suffering outbreaks. In contrast, CoTS eDNA was absent from 'post-outbreak' reefs after populations collapsed and from 'pre-outbreak' reefs. In linear models, CoTS densities explained a high amount of
\end{abstract}

Topic Editor Morgan S. Pratchett

Electronic supplementary material The online version of this article (https://doi.org/10.1007/s00338-018-1734-6) contains supplementary material, which is available to authorized users.

Sven Uthicke

suthicke@aims.gov.au

1 Australian Institute of Marine Science, PMB No. 3, Townsville MC, Qld 4810, Australia

2 Department of Marine Science, University of Otago, Dunedin 9016, New Zealand variance of eDNA concentrations, both for water samples taken at the depth of transects $\left(R^{2}=0.60, p<0.0001\right)$ and on the sea surface $\left(R^{2}=0.46, p=0.0004\right)$. The proportion of samples above LOQ was also correlated with CoTS densities, with a similar amount of variance explained as for the concentration (underwater $R^{2}=0.68, p<0.0001$; surface $\left.R^{2}=0.49, p=0.0004\right)$. We conclude that, after consideration of sampling locations and times, this method is promising for CoTS population monitoring and early detection of outbreaks and might supplement or replace traditional monitoring. Development of automated samplers and possibly on board PCR in the future will further improve early detection.

Keywords Coral reef crisis - Nuisance species . Population outbreaks $\cdot$ eDNA

\section{Introduction}

The Great Barrier Reef Marine Park (GBR) is globally one of the largest marine protected areas and has iconic status as a world heritage site. However, over the last three decades coral cover has been reduced by about $50 \%$ (De'ath et al. 2012). Prior to recent climate change related coral bleaching events in 2016 and 2017 (Hughes et al. 2017), outbreaks of the Pacific species of coral eating sea star, Acanthaster cf. solaris (crown-of-thorns seastar, CoTS), caused an estimated $42 \%$ of the coral loss (De'ath et al. 2012). Currently, the GBR is experiencing its fourth major CoTS outbreak since the 1960s (Pratchett et al. 2014, 2017), while at the same time, many other coral reefs in the Indo-Pacific region are being severely impacted by CoTS. This includes reefs in French Polynesia (Kayal et al. 
2012), Indonesia (Baird et al. 2013) and Okinawa, Japan (Nakamura et al. 2014).

CoTS have a 'boom and bust' life cycle (Uthicke et al. 2009), and reasons for outbreaks ('boom') and subsequent population breakdown ('bust') are not fully resolved. It is hypothesised that outbreaks are promoted through an increased survivorship of the planktivorous CoTS larvae in response to greater phytoplankton biomass (Uthicke et al. 2015b; Pratchett et al. 2017; Uthicke et al. 2018) associated with land runoff (nutrient hypothesis, e.g. Birkeland 1982; Brodie et al. 2005; Fabricius et al. 2010). An alternative view of outbreak causes is the 'predator removal hypothesis', where top-down reductions in predation on adult or juvenile CoTS are proposed as the mechanism of population increase (Pratchett et al. 2014; Cowan et al. 2017). Most likely a combination of factors including food concentrations, predator densities, sea surface temperature and other climatic factors is responsible for the outbreaks (Black et al. 1995; Uthicke et al. 2015b; Wooldridge and Brodie 2015). CoTS outbreaks on the GBR are usually first detected in northern areas of the GBR between Cairns and Cooktown (the 'initiation box') and progressively move south at a rate of approximately $60 \mathrm{~km} \mathrm{yr}^{-1}$ due to larval dispersal (Vanhatalo et al. 2017).

Knowledge of the exact time and location of the outbreaks is important for understanding the dynamics and drivers of outbreaks, and early detection would allow efficient timely intervention and management. For example, due to limited temporal and spatial resolution of the monitoring, it is not known where exactly in the initiation box primary outbreaks first occur and whether individual reefs or several reefs have simultaneous primary outbreaks (Pratchett et al. 2014). In addition, routine monitoring for CoTS on the GBR is conducted using manta tows, a technique which might only detect $5 \%$ of the individuals present due to cryptic behaviour and low visibility of juveniles (Fernandes et al. 1990). Thus, developing improved detection tools and implementing early warning systems are a priority of future CoTS management (Pratchett et al. 2017).

Environmental DNA (eDNA) is defined as genetic material obtained directly from environmental samples (i.e. soil, sediment, water column) without any obvious signs of biological source material (Thomsen and Willerslev 2015). The sources of this DNA may be shed skin cells, and excretion of mucus, urine or faeces (Rees et al. 2014). Some studies include DNA from pelagic larvae in the definition of eDNA (Richardson et al. 2016). Measuring aquatic eDNA was initially tested in small freshwater ponds to detect introduced species (Ficetola et al. 2008). Subsequently, eDNA has become a widely used tool in freshwater environments to, for instance, detect invasive species such as salamander (Fukumoto et al. 2015) or carp
(Jerde et al. 2013; Hunter et al. 2017), or to detect rare or threatened species (Rees et al. 2014).

Given the large body of water involved and the more dynamic physical nature (i.e. tides, ocean currents, vertical mixing), eDNA in marine environments is likely at lower concentrations and thus harder to detect. Indeed, initial attempts to detect an invasive mud crab species (Rhithropanopeus harrisii) in the Baltic Sea proved difficult (Forsström and Vasemägi 2016). However, several recent studies have successfully used eDNA to quantify fish or describe fish diversity in the marine environment (Thomsen et al. 2012; Yamamoto et al. 2016) using both specific primers or metabarcoding approaches. Methods for monitoring groups that are not well described such as harmful algae and faecal indicators (Yamahara et al. 2015) or Octopus vulgaris (Mauvisseau 2017) have also recently been developed. A study on a coral reef used universal barcoding primers to describe Eukaryote diversity across several major taxa (Stat et al. 2017). The use of eDNA from water samples has also been applied to a population genetic study on whale shark aggregations (Sigsgaard et al. 2016).

Similar to other phyla (Hebert et al. 2003), the mitochondrial gene cytochrome oxidase (COI) can be used for species identification ('barcoding') in echinoderms (Vogler and Monaghan 2007; Ward et al. 2008; Uthicke et al. 2010). We recently developed CoTS-specific COI primers to identify (Uthicke et al. 2015a) and quantify (Doyle et al. 2017) CoTS larvae in plankton samples. Here, we demonstrate that the same primers and TaqMan probe can be used to amplify 'free' DNA (as opposed to DNA in larvae) in water samples to detect post-settlement CoTS. To achieve this, we first adapted our laboratory method from qPCR to digital droplet PCR to improve the limit of quantification. This technique is assumed to have a several orders of magnitude higher sensitivity and precision than qPCR, and is less vulnerable to PCR inhibition and independent of external standards (Hindson et al. 2011; Hunter et al. 2017). Second, we conducted a series of aquarium experiments to validate the method and establish the rate at which adult CoTS release DNA. Third, we tested our method by collecting water samples on 11 coral reefs varying in CoTS population densities between extreme $\left(>50\right.$ Ind. $100 \mathrm{~m}^{-2}$ ) and 0 individuals. The latter include both pre-outbreak reefs with very few CoTS and postoutbreak reefs following CoTS population collapse.

\section{Materials and methods}

\section{Aquarium experiments}

In an initial aquarium experiment at AIMS's National Sea Simulator facility between the 27 April 2017 and 10 May 
2017, we tested for a relationship between seastar biomass and the quantity of CoTS eDNA. Water temperatures during this period ranged from $25{ }^{\circ} \mathrm{C}$ to $26^{\circ} \mathrm{C}$. A $10,000-1$ tank was set up with a seawater flow rate of $13.91 \mathrm{~min}^{-1}(2$ turnovers $\mathrm{d}^{-1}$ ). The tank was allowed to equilibrate for 1 week (equivalent to 14 turnovers) before initial blank water samples (2 1,n=4) were taken. Subsequently, the wet weight of a single CoTS was determined and the specimen added carefully to the tank. The tank was then allowed to equilibrate $48 \mathrm{~h}$ before water samples were taken as per above. After sampling, a second individual was added and the equilibration/sampling procedure repeated. This process of doubling the number of CoTS in the tank and sampling the water continued until 16 animals were in the tank (=6 sampling occasions including the initial blank samples, 1, 2, 4, 8 and 16 individuals). All water samples from this experiment were filtered through both a Sterivex $0.22-\mu \mathrm{m}$ polyethersulphone (Millipore catalogue \# SVGPL10RC) filter and a 47-mm 1- $\mu \mathrm{m}$ cellulose nitrate filter ( $\mathrm{CN}$ filter) to compare DNA capture efficiency of the filters (see below). After filtration, Sterivex filters were capped at both ends and the $\mathrm{CN}$ filters were placed in 2-ml cryotubes. Inlet water was also sampled as a control at the beginning and end of the experiment. All filters were stored at $-80{ }^{\circ} \mathrm{C}$ until analysis. All equipments used to conduct filtration were cleaned with $10 \%$ bleach before and after use.

\section{DNA extraction}

Filters were extracted using slightly modified versions of the Qiagen DNeasy Blood and Tissue extraction kit. For Sterivex filters, Qiagen buffer ATL $(0.9 \mathrm{ml})$ and proteinase $\mathrm{K}\left(0.1 \mathrm{ml}, 20 \mathrm{mg} \mathrm{ml}^{-1}\right)$ were added directly onto the filter and the capped filter was incubated $\left(56^{\circ} \mathrm{C}\right)$ overnight with constant rotation. Subsequently, Sterivex filters were briefly centrifuged to remove liquid and bubbles from the filter inlet and Qiagen buffer AL (1 ml) was added. The Sterivex filter was recapped and incubated for a further $30 \mathrm{~min}\left(56^{\circ} \mathrm{C}\right)$ with constant rotation. A new 5-ml syringe was used to expel the ATL/proteinase K/AL lysis mixture into a 5-ml tube. Ethanol $(1 \mathrm{ml})$ was added to this lysis mixture and mixed well. The ATL/proteinase K/AL/ethanol mixture was then added to a Qiagen spin column as per the manufactures' instructions. Qiagen spin columns were washed with $500 \mu$ l Qiagen wash buffer AW1 followed by centrifugation at $10,000 \times \mathrm{g}$ for $1 \mathrm{~min}$ and then washed with $500 \mu$ l Qiagen wash buffer AW2 followed by centrifugation at $20,000 \times \mathrm{g}$ for $3 \mathrm{~min}$. DNA was eluted from Qiagen spin columns with $3 \times 50 \mu \mathrm{l} \mathrm{TE} \mathrm{T.1}_{0}$.

For CN filters, Qiagen buffer ATL $(0.81 \mathrm{ml})$ and proteinase $\mathrm{K}\left(90 \mu \mathrm{l} 20 \mathrm{mg} \mathrm{ml}^{-1}\right.$ proteinase $\left.\mathrm{K}\right)$ were added which was followed by an overnight incubation $\left(56{ }^{\circ} \mathrm{C}\right)$ with constant rotation. Qiagen buffer $\mathrm{AL}$ was then added $(0.9 \mathrm{ml})$, and the samples were incubated at $56{ }^{\circ} \mathrm{C}$ for 30 min with constant rotation. After this second incubation, $0.8 \mathrm{ml}$ of the ATL/proteinase $\mathrm{K} / \mathrm{AL}$ lysis mixture was added to a new 2-ml microtube containing $400 \mu$ l ethanol and mixed thoroughly. Application to the spin column, washing and elution of DNA were conducted as per the Sterivex procedure.

\section{Quantitative PCR and digital (droplet) PCR assay}

The development of the eDNA assay was based on qPCR used for CoTS larval quantification (Doyle et al. 2017). Following initial aquarium tests we decided to move the assay to digital droplet PCR (ddPCR) that provides lower limit of detection (see below). Digital droplet PCR was conducted using the Bio-Rad QX200 ddPCR system. The qPCR assay described in Doyle et al. (2017) was directly transferred to ddPCR using the same primer and hydrolysis probe concentrations. A $25-\mu l$ ddPCR reaction was prepared using a CAS-1200 liquid handling robot (Qiagen). Each reaction contained 12.5- $\mu$ l Bio-Rad ddPCR supermix for probes (no dUTP), 400-nM forward primer (CoTSCOI-F-1321), 400-nM reverse primer (CoTS-COI-R1446), 100-nM hydrolysis probe (5' FAM-CTATCTCATCCATAGGCAGCAC) and EcoR1 restriction enzyme (2 units per reaction). All samples were tested in duplicate. Twenty microlitres of the PCR mix was pipetted into the sample chambers of a Droplet Generator DG8 Cartridge (Bio-Rad, cat no. 1864008), and $70 \mu \mathrm{l}$ of the Droplet Generation Oil for Probes (Bio-Rad, cat no. 186-3005) was added to the appropriate wells. The cartridges were covered with DG8 Gaskets (Bio-Rad, cat no. 1863009) and placed in a QX200 Droplet Generator (Bio-Rad) to generate the droplets. After droplet generation, the droplets $(40 \mu \mathrm{l})$ were carefully transferred to a semi-skirted 96-well PCR plate (Bio-Rad, cat no. 12001925). The PCR plate was sealed with pierceable foil (Bio-Rad, cat no. 181-4040), and PCR run under the following conditions: $95^{\circ} \mathrm{C}$ for $10 \mathrm{~min}, 1$ cycle; $95{ }^{\circ} \mathrm{C} 30 \mathrm{~s}, 60{ }^{\circ} \mathrm{C} 1 \mathrm{~min}, 40$ cycles; $98{ }^{\circ} \mathrm{C}, 10 \mathrm{~min}$, 1 cycle; $10{ }^{\circ} \mathrm{C}$ infinite hold. Droplets were then read on a QX200 droplet reader (Bio-Rad). False positive rate determination typically involves the measurement of positive droplets in a population of wild type and mutant genes. In environmental DNA (eDNA) research, this is not an attainable method. Alternatively, we sampled water from a mesocosm aquarium at the Australian Institute of Marine Science SeaSim facility that contained a variety of marine organisms including coral, fish, molluscs and nonCoTS echinoderms. Six 2-1 water samples were taken from the mesocosm and filtered on separate $\mathrm{CN}$ filters. DNA was extracted from the $\mathrm{CN}$ filters as described and normalised to $1 \mathrm{ng} \mu \mathrm{l}^{-1}$. Six technical replicates of each filter were 
analysed using the ddPCR method described giving a total of 36 wells. Blank filter extractions, positive controls and no template controls were also included in the assay.

\section{Field sampling and CoTS density}

Field collections were conducted on four field trips between June 2016 and August 2017, covering reefs in the Cooktown, Innisfail and Ingham to Townsville regions (Table 1, Electronic Supplementary Material, ESM Table 1S). In general, we only collected between May and August outside the known CoTS summer spawning season (Pratchett et al. 2014). This was to avoid potential contamination of the samples through CoTS gametes, embryos or larvae suspended in the water column. The exception was one trip to the Cooktown region in December 2016, designed to test if potential contamination was an issue through parallel plankton and eDNA sampling. However, at the time of the trip the CoTS population in that region had collapsed and all plankton samples were negative (Uthicke and Doyle, unpublished data). Thus, contamination from CoTS larvae was unlikely for those samples. In addition to avoiding the spawning season, samples were filtered through $70-\mu \mathrm{m}$ filters to remove potential embryo and larval contamination. Water samples were collected in 2-1 plastic (HDPE) bottles cleaned with $10 \%$ bleach between samplings. To allow submersion, sampling containers were filled with fresh water prior to taking them into the field. Surface sampling of two samples per site was undertaken from tender vessels by semi-submersing bottles after emptying fresh water. Underwater samples were taken after evacuating freshwater from the bottle using a SCUBA air hose. Two additional freshwater filled bottles were taken into the field at each sampling occasion to serve as procedural controls.

At most sites, we conducted CoTS counts in parallel with water collections on 1-3 transects (Table 1). Transects consisted of 50-m tape measures laid out along

Table 1 Number of transects counted for Acanthaster cf. solaris surveys, densities and the number of eDNA samples collected at each location. Further details on locations and filters used are given in ESM Table S1

\begin{tabular}{|c|c|c|c|c|c|c|}
\hline $\begin{array}{l}\text { Reef/ } \\
\text { location }\end{array}$ & $\begin{array}{l}\text { No. of } \\
\text { transects }\end{array}$ & $\begin{array}{l}\text { Densities } \\
\text { (Ind. } 100 \mathrm{~m}^{-2} \text { ) }\end{array}$ & $\begin{array}{l}\text { Density range } \\
\text { (Ind. } 100 \mathrm{~m}^{-2} \text { ) }\end{array}$ & $\begin{array}{l}\text { Underwater samples } \\
\text { (no.) }\end{array}$ & $\begin{array}{l}\text { Surface samples } \\
\text { (no.) }\end{array}$ & $\begin{array}{l}\text { Transect depth } \\
\text { (m) }\end{array}$ \\
\hline Peart Rf./1 & 1 & 1 & - & 6 & 2 & 7 \\
\hline Peart Rf./2 & 1 & 4 & - & 6 & 2 & 2 \\
\hline Peart Rf./3 & 1 & 6 & - & 6 & 2 & 2 \\
\hline Rib Rf./1 & 2 & 35.2 & $25.5-45.0$ & 6 & 2 & $7-9$ \\
\hline Rib Rf./2 & 2 & 58 & $20.5-95.5$ & 6 & 2 & $4-7$ \\
\hline Rib Rf./3 & 2 & 0 & 0 & 6 & 2 & $1-3$ \\
\hline Trunk Rf./1 & 2 & 5.8 & $4.5-7.0$ & 6 & 2 & $3-7$ \\
\hline Trunk Rf./2 & 2 & 0.8 & $0-1.5$ & 6 & 2 & $3-7$ \\
\hline $\begin{array}{l}\text { Walker Rf./ } \\
1\end{array}$ & 3 & 1.7 & $1.0-2.0$ & 6 & 2 & $3-7$ \\
\hline $\begin{array}{l}\text { Walker Rf./ } \\
2\end{array}$ & 2 & 4.3 & $3.0-5.5$ & 6 & 2 & $3-7$ \\
\hline Bramble Rf. & 3 & 4.5 & $3.0-6.0$ & 6 & 2 & $3-6$ \\
\hline Rib Rf./4 & 3 & 2.5 & $1.0-4.0$ & 6 & 2 & $2-6$ \\
\hline Rib Rf./5 & 3 & 4.2 & $1.5-8.0$ & 6 & 2 & $2-8$ \\
\hline Rib Rf./6 & 2 & 6.8 & $2.0-11.5$ & 6 & 2 & $2-8$ \\
\hline $\begin{array}{l}\text { Davies } \\
\text { Reef/1 }\end{array}$ & 4 & 0 & 0 & 6 & 2 & $5-7$ \\
\hline $\begin{array}{l}\text { Davies } \\
\text { Reef/2 }\end{array}$ & 2 & 0 & 0 & 6 & 2 & $6-7$ \\
\hline $\begin{array}{l}\text { Broadhurst } \\
\text { Rf. }\end{array}$ & 2 & 0 & 0 & 6 & 2 & $6-8$ \\
\hline Eyrie Rf. & 0 & 0 & & 4 & 0 & \\
\hline $\begin{array}{l}\text { Lizard } \\
\text { Island }\end{array}$ & 0 & 0 & & 5 & 40 & \\
\hline Yonge Rf. & 0 & 0 & & 0 & 2 & \\
\hline No name Rf. & 0 & 0 & & 0 & 2 & \\
\hline
\end{tabular}


similar depth (depth range: 2-9 $\mathrm{m}$, Table 1). Divers subsequently searched for and counted CoTS in a belt of $2 \mathrm{~m}$ on either side of the transect $\left(=\mathrm{a}\right.$ total of $200 \mathrm{~m}^{2}$ per transect). eDNA samples were collected in duplicate at 10 , 25 and $40 \mathrm{~m}$ along the first transect at each site, about $0.5-1.0 \mathrm{~m}$ from the seafloor. Given the paucity of CoTS in the Cooktown region, we did not conduct individual transects, but rather searched larger areas via scuba or snorkel searches. In total, we searched about 6 person $\mathrm{h}$ on Lizard Island (1 CoTS observed), $3 \mathrm{~h}$ on Eyrie Rf. (1 CoTS) and $1.5 \mathrm{~h}$ each on No Name and Yonge Reefs (0 CoTS). Thus, we assumed a density of 0 Ind. $\mathrm{m}^{-2}$ for these locations. This is supported by discussions with research station staff (L. Vail and A. Hoggett, personal communication) and by monitoring data from the AIMS Long Term Monitoring Team and others (ESM Table S2).

Field samples collected during 2016 (see Table 1) were filtered through Sterivex filters. We subsequently moved to filtering via CN filters for samples collected in 2017 as logistics improved and troubleshooting of filtering was reduced. For example, we found that Sterivex filters occasionally became clogged, and consequently, the final filtered volume was altered. We also found that cleaning procedures for the $\mathrm{CN}$ filters were more time efficient compared to cleaning procedures for the Sterivex filters. During this transition, we conducted experiments to demonstrate comparability of filtration methods along with comparisons of qPCR and ddPCR. Our initial aquarium biomass experiments (see above) were found to contain much higher CoTS DNA and total DNA than we found in the field; therefore, to compare filtering methods at field relevant levels, we conducted a trial (6 June 2018, water temperature: $23.0^{\circ} \mathrm{C}$ ) using the same tank set-up described above containing a single CoTS. From this water, we tested neat, $1 / 10$ and $1 / 100$ diluted water $(n=6)$ using inlet seawater to dilute samples and analysed as described above. To compare analysis methods of qPCR and ddPCR, we analysed all samples collected from Peart Reef in 2016 using both qPCR and ddPCR.

\section{Statistical analyses}

We used general linear models to test for relationships for pairs of variables. Specifically, four comparisons were conducted against estimates of average CoTS densities per site: (1) the average eDNA concentration per site of samples taken in situ; (2) the percentage of in situ samples per site above the limit of quantification (LOQ); (3) the average eDNA concentration per site of samples taken on the water surface; and (4) the percentage of surface samples per site above the LOQ. In addition, we tested if concentrations and \% above LOQ were related between underwater and surface samples using Pearson's correlation coefficient. All variables were $\log 10(\mathrm{x})$-transformed prior to analyses, with zero values replaced by $0.5 \times$ the minimum value observed for the respective variable.

\section{Results}

\section{Method development and aquarium tests}

In aquarium tests, CoTS eDNA was readily detectable using quantitative PCR (Fig. 1). DNA concentrations on the $\mathrm{CN}$ filters increased linearly with CoTS biomass $(0.8-14.65 \mathrm{~kg})\left(R^{2}=0.99, t=39.62, p<0.0001\right)$. A linear regression also explained a large amount of the variance for Sterivex filters $\left(R^{2}=0.81, t=4.76, p=0.0089\right)$, although the samples at the highest concentrations fall below the regression line and suggest filter saturation occurs for these filters. All controls during this experiment were negative for CoTS DNA.

In an equilibrium system, the release rate (in this case eDNA) is equivalent to the concentration multiplied by flow rate. The release rate of eDNA (based on CN filters) was significantly related to CoTS number in the aquaria (linear model, $t=24.66, p<0.0001, R^{2}=0.99$ ). Based on the slope of this model, the release rate of an individual of the size range tested here was $2,062,718$ copies $\min ^{-1}$ (1 $\mathrm{SE}=83,636$ copies $\mathrm{min}^{-1}$ ).

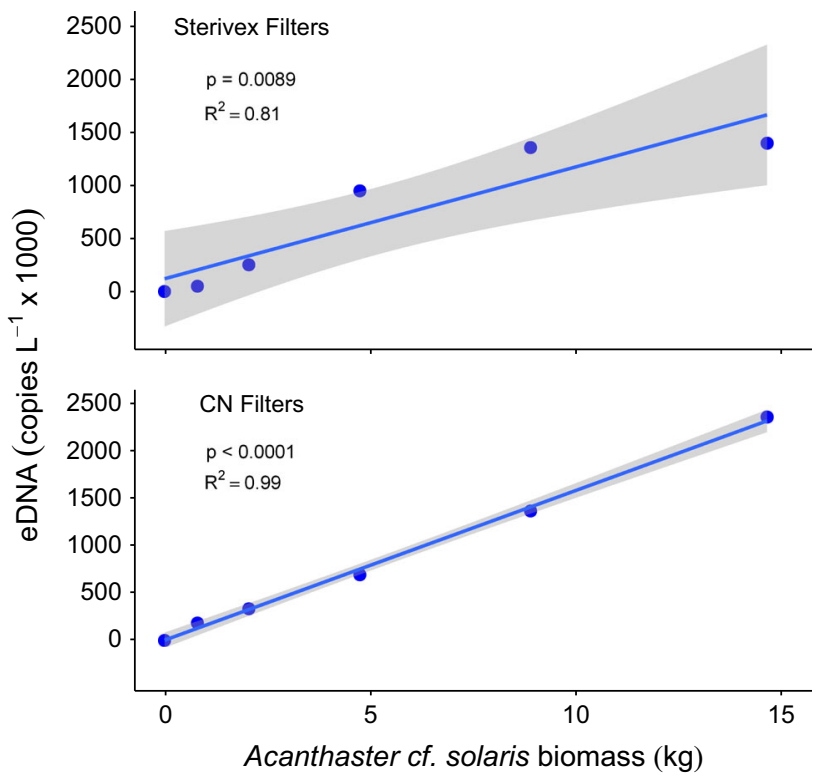

Fig. 1 eDNA concentration in a 10,000 1 aquarium with increasing amounts of Acanthaster cf. solaris biomass representing zero to 16 adult individuals. Water samples were filtered with either Sterivex or $\mathrm{CN}$ filters. A linear regression is fitted for the Sterivex (copies $1^{-1}=119,711+105,272 \times A$. cf. solaris biomass) and CN filters (copies $1^{-1}=1871+158,318 \times A$. cf. solaris biomass). The grey shaded area represents $1 \mathrm{SE}$ of each fit 
To achieve a lower limit of quantification (LOQ), we adapted our hydrolysis probe based qPCR technique to ddPCR. A subset of field samples $(N=13)$ demonstrated that both methods gave comparable results over a range of concentrations $\left(p<0.0001, R^{2}=0.96\right)$, with a slope indistinguishable from 1 (slope $=0.96, \mathrm{SE}=0.05)(\mathrm{ESM}$ Fig. S1). The LOQ for qPCR was determined at 225 copies per reaction in our previous study (Doyle et al. 2017). For the false positive rate (FPR) determination in ddPCR, we measured a total of 9 droplets over the 36 test wells, giving a FPR of 0.25 droplets per well. Based on this FPR, we determined an LOQ of 5 positive droplets per well for the ddPCR assay using Bio-Rad lookup tables. This equates to 8 copies per well at the upper $95 \%$ confidence interval.

As we changed from Sterivex filters to $\mathrm{CN}$ filters after the 2016 field samples, we tested if the same amount of $A$. cf. solaris eDNA was captured on different filter types in three different dilutions, spanning the range of field measured eDNA (see below). These tests were conducted using ddPCR. Two-factor analysis of variance confirmed differences in eDNA concentrations dilutions, but not between filter types, nor an interaction of dilution and filter (ESM Table S3). Measured concentrations decreased in accordance with the dilution of the original sample, and values between the two filters were very similar (ESM Fig. S2). Hence, we concluded that changing the filters after the initial sampling period had no outcome on the results.

\section{Field analyses}

We selected 11 GBR reefs during the 15-month study period to collect eDNA samples and data on CoTS density (Table 1). This included two reefs in the Far Northern Section that previously had significant outbreaks, two in the same region with no outbreak history, five reefs in the Central Section of the GBR with present active outbreaks and 2 reefs with no active outbreak approximately 55-65 km from the current outbreak front near Loadstone Reef (ESM Table S2).

CoTS eDNA was not detected on post-outbreak reefs, nor other reefs in the Northern Section several yrs after CoTS populations collapsed in that area (Fig. 2). Similarly, there was no eDNA detection on the two 'pre-outbreak' reefs south of the current outbreak front. CoTS DNA was, however, detectable on all reefs suffering current outbreaks, with concentrations of up to 18,147 and 10,814 copies $1^{-1}$ measured in underwater and surface samples, respectively (Fig. 2, ESM Table S1). In total, 76.2\% (64/ 84 ) of underwater samples and $64.3 \%$ (18/28) of surface samples on reefs in the current outbreak area were above LOQ.

Concentrations of eDNA increased significantly with increasing CoTS densities (Table 2). A linear model explained $60 \%$ of the variance in eDNA concentration in samples collected at the transect depths by CoTS density, while $46 \%$ of the variation in surface samples was explained (Table 2, Fig. 3). In addition to eDNA concentration, we explored the proportion of samples above the LOQ as a metric to indicate CoTS presence. Linear models indicated that CoTS densities explained a similar amount of variance in that metric (underwater $R^{2}=0.68$, surface $R^{2}=0.49$, Fig. 3) as for concentrations. This was despite the lower number of samples taken on the surface (Table 1). In this analysis, for both underwater samples (correlation analysis, $R^{2}=0.55, p=0.0001$ ) and surface samples $\left(R^{2}=0.55, p=0.0004\right)$, the average eDNA concentration and the proportion of positive samples were correlated.

Each sampling set included two blank freshwater samples taken into the field, with one returned as is and the second dipped into the seawater. None of these controls exhibited eDNA concentrations above the LOQ.

\section{Discussion}

In freshwater environments, eDNA is now frequently used to detect invasive (Fukumoto et al. 2015), rare or threatened species (Rees et al. 2014). Although dilution will be much larger in the ocean due to larger water volumes and greater horizontal and vertical mixing, eDNA in the marine environment has the potential to become a core tool for monitoring (Kelly et al. 2014). We tested if eDNA approaches can be applied for early detection and monitoring of the crown-of-thorns seastar (CoTS) outbreaks. We demonstrated in aquarium experiments that free CoTS eDNA increases with density/biomass. We then demonstrated that eDNA was detectable at low concentrations and correlated with CoTS densities in the field.

Droplet digital PCR (ddPCR) is a relatively new method for absolute quantification of nucleic acids (Hindson et al. 2011). ddPCR has a lower detection limit and is less prone to PCR inhibition than qPCR (Hunter et al. 2017). The latter fact means that total DNA for ddPCR can be much higher concentrated (i.e. more sample volume collected), which further reduces the overall LOQ of the assay. Thus, DNA from 2-1 water samples collected here could be measured at neat concentrations (typical extracted DNA concentrations 2-10 ng $\mu \mathrm{l}^{-1}$ ), whereas qPCR samples tested, required a tenfold dilution due to the effect of PCR inhibition. Correlation between qPCR and ddPCR is important when translating methods, and we found this to be the case for our study. For the present eDNA work, samples were often at the lower limits of quantification when using qPCR. The LOQ for the qPCR method used herein is 225 copies per reaction, with the variability too 
Fig. 2 Density estimates of Acanthaster cf. solaris (left) and eDNA concentration on 11 reefs of the Great Barrier Reef,

Australia

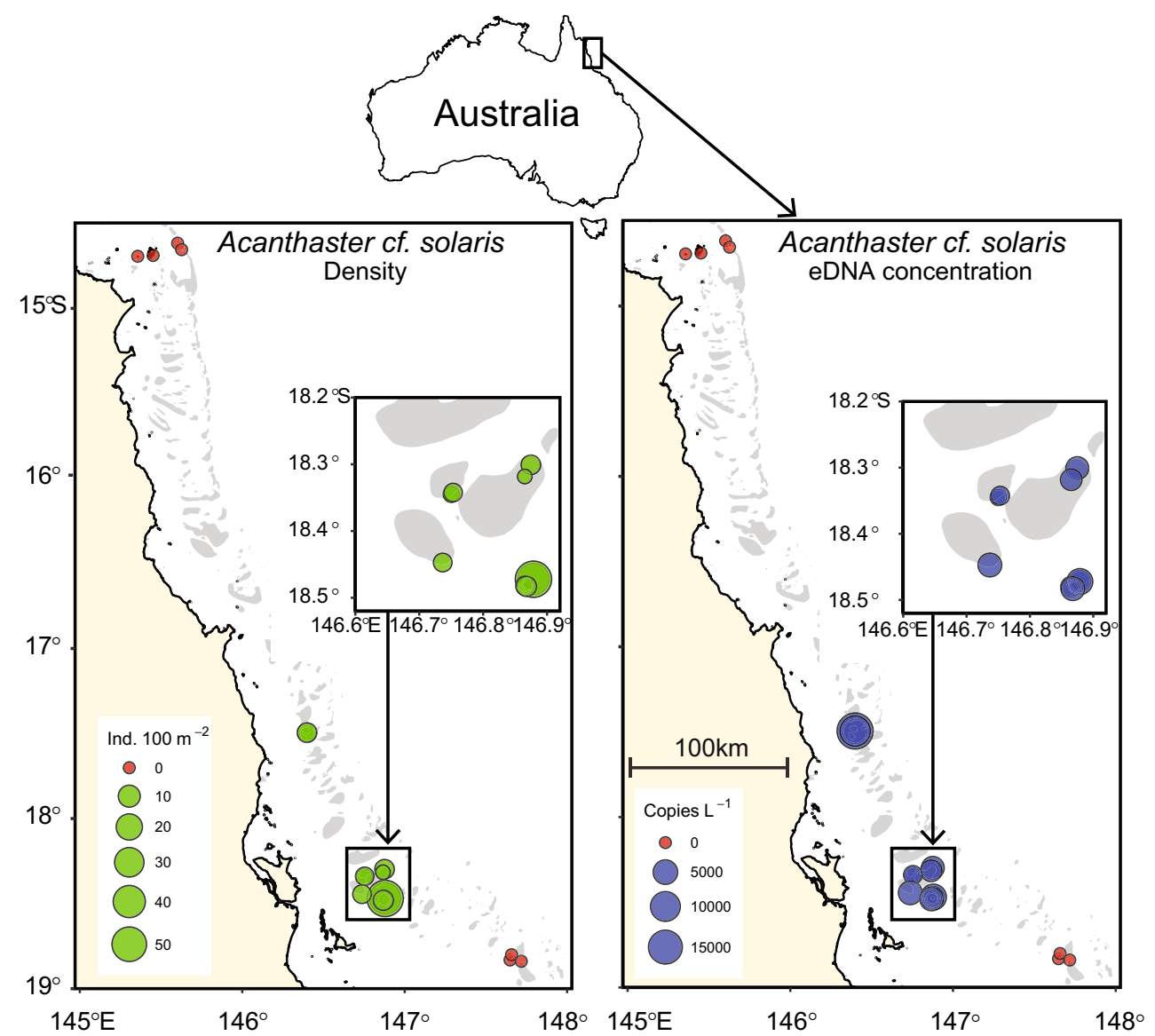

Table 2 Results of linear models comparing eDNA concentrations and the percentage of samples above the limit of quantification (LOQ) collected at depth (underwater) or on the ocean surface (surface), and densities of Acanthaster cf. solaris (CoTS density)

\begin{tabular}{lcrrrl}
\hline Comparison & Estimate & SE & $t$ & $p$ & Model $R^{2}$ \\
\hline Underwater concentration versus CoTS density & \\
Intercept & 2.7515 & 0.1117 & 24.62 & $<0.0001$ & 0.60 \\
Slope & 0.8807 & 0.1575 & 5.59 & $<0.0001$ & \\
Surface concentration versus CoTS density & & \\
Intercept & 2.5485 & 0.1048 & 24.31 & $<0.0001$ & 0.46 \\
Slope & 0.6263 & 0.1477 & 4.24 & 0.0004 & \\
Underwater \% & $>$ LOQ versus CoTS density & & \\
Intercept & 1.3249 & 0.0803 & 16.50 & $<0.0001$ & 0.68 \\
Slope & 0.6763 & 0.1086 & 6.23 & $<0.0001$ & \\
Surface \% > LOQ versus CoTS density & & \\
Intercept & 1.5790 & 0.0639 & 24.70 & $<0.0001$ & 0.49 \\
Slope & 0.3878 & 0.0883 & 4.39 & 0.0004 & \\
\hline
\end{tabular}

All variables were $\log 10(\times)$-transformed prior to analyses. For transformation, zero values were replaced by $0.5 \times$ the minimum value observed for the respective variable

great for concentrations less than this (Doyle et al. 2017). Thus, in addition to potentially less problems due to PCR inhibition, a lower detection and quantification limit is a clear advantage of ddPCR.
Several filtration methods have been applied to aquatic eDNA (Turner et al. 2014; Minamoto et al. 2016; Spens et al. 2017). Sterivex filter cartridges provide a level of 'protection' from cross-contamination, but these filters were more prone to clogging and filter saturation in our study. Our decision to change to $\mathrm{CN}$ filters was driven by the need to simplify filtration logistics. Aquarium comparisons of Sterivex and $\mathrm{CN}$ filters demonstrated that Sterivex filters did indeed saturate and that the total DNA captured by the Sterivex filters reached a plateau at high DNA concentrations. This was not the case for $\mathrm{CN}$ filters (Fig. 1), and regressions between CoTS biomass and DNA captures were found to be less variable for $\mathrm{CN}$ filters. At field relevant (i.e. lower than in the aquarium experiment) CoTS eDNA concentrations, $\mathrm{CN}$ and Sterivex yielded the same results (ESM Fig. 2). In short, we were satisfied that moving from Sterivex filters to $\mathrm{CN}$ filters did not bias results, while it improved sampling logistics and possibly precision at higher concentrations.

Based on the aquarium experiments, eDNA release from individual CoTS was in the range of $2 \times 10^{6}$ copies $\mathrm{min}^{-1}$. These values are substantially higher than those measured in fish (Maruyama et al. 2014; Klymus et al. 2015). Although we do not know the number of mitochondria in 
Fig. 3 Linear models of eDNA in water samples taken in situ (underwater) and on the sea surface (surface) as a function of Acanthaster cf. solaris densities on reefs of the Great Barrier Reef, Australia.

Response variables are either the average concentration per site (eDNA) or the proportion of samples above the limit of quantification (LOQ). The grey shaded area represents $1 \mathrm{SE}$ of each fit. Regression equations (intercepts and slopes) for the models are given in Table 2
Under Water
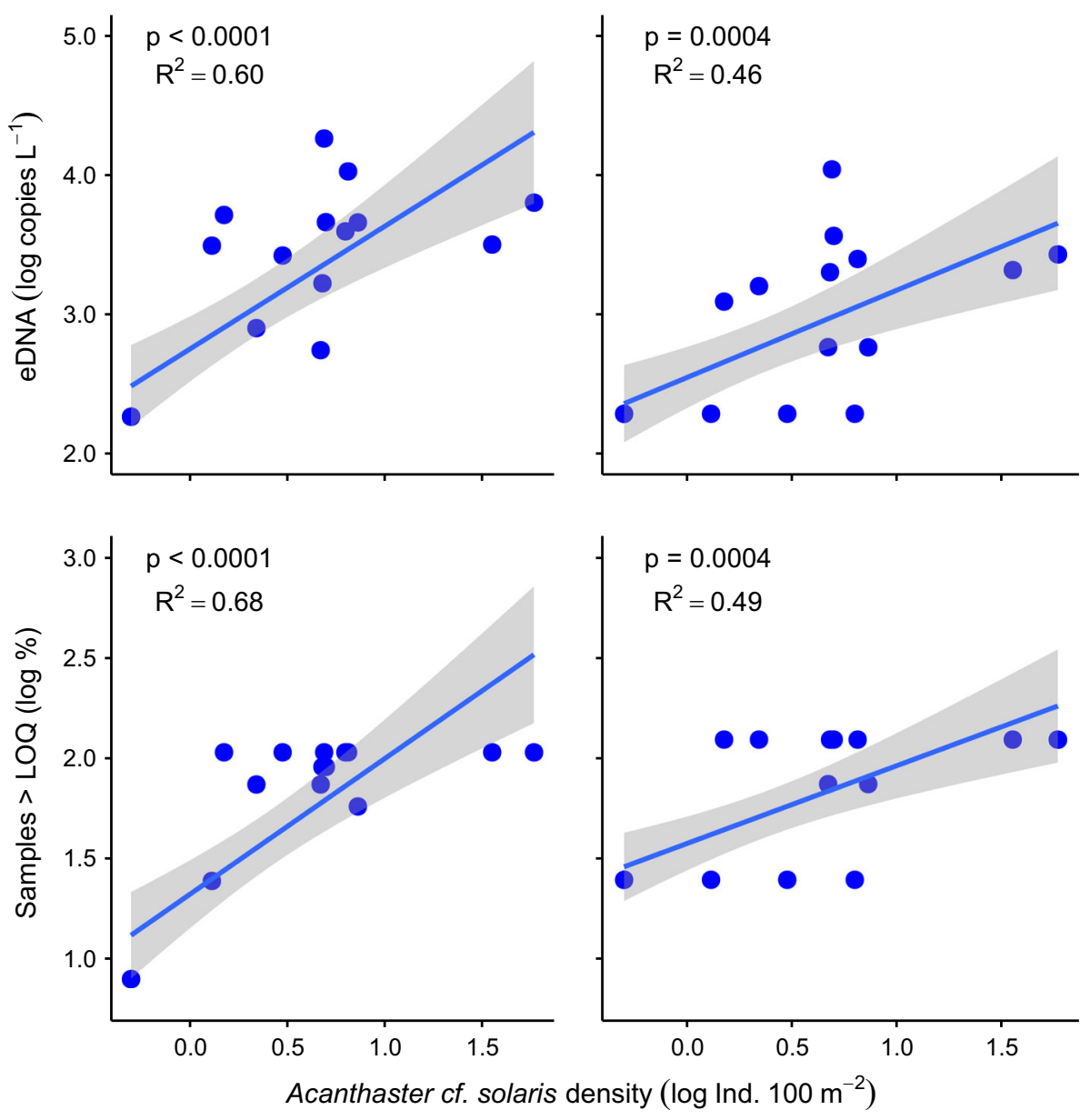

Surface

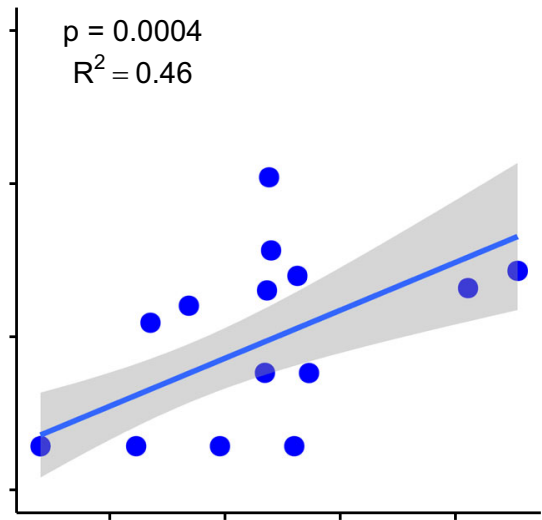

$p=0.0004$
$R^{2}=0.49$ adult CoTS cells, we showed earlier that oocytes, eggs and 2-cell stage embryos had over a million mtDNA copies per cell. If somatic adult cells had similar or somewhat lower numbers of mitochondria, these release rates were equivalent to several cells per min. A caveat for these estimations is the possibility that animals in aquaria experiments may shed more DNA in the form of greater release of mucus and cells associated with stress. In addition, eDNA release rates can depend on the diet of aquatic organisms as was demonstrated for invasive carp (Klymus et al. 2015), while it is also likely that some of the DNA degraded during the experiment (Bylemans et al. 2018), a factor that was not taken into consideration. Further experimentation on DNA turnover is required to understand these factors.

The eDNA concentrations measured in the field corresponded well to the observed occurrence of CoTS over $>500 \mathrm{~km}$ of the GBR investigated here. Outbreaks usually start in the 'initiation box' between Cairns and Cooktown, and probably at the Northern End of this box (Pratchett et al. 2014; 2017), corresponding to the Cooktown region reefs sampled in this study. No water sample collected from that region contained CoTS eDNA above the limit of quantification (LOQ). Our surveys, and additional data (ESM Table S2), confirmed that the outbreak in that region has collapsed. Although not an explicit aim of our study, it is also of benefit to know that CoTS eDNA signals disappear from reef waters after population collapse. By contrast, $76.2 \%$ of underwater samples and $64.3 \%$ of surface samples on reefs in the present outbreak area were above the LOQ. The two reefs south of the present outbreak showed no detectable CoTS eDNA. Given that these are approximately $60 \mathrm{~km}$ from the nearest reported outbreak front and outbreaks can spread about $60 \mathrm{~km} \mathrm{yr}^{-1}$ (Vanhatalo et al. 2017), it is likely that outbreaks on those reefs are imminent. Indeed, it will be interesting to continue eDNA and CoTS monitoring on those reefs to test at which stage outbreaks can be detected using eDNA, with such information increasing our understanding of the dynamics and mechanism of outbreaks.

eDNA surveys have developed into important tools for aquatic biodiversity monitoring (Yamamoto et al. 2016, 2017; Stat et al. 2017) and the detection of rare and introduced species (Rees et al. 2014). To our knowledge, this is the first time it has been demonstrated that eDNA 
can be used for monitoring marine nuisance species. Although one study demonstrated detection of eDNA from the introduced crab species in the Baltic Sea, the authors concluded that detection rates were too low (Forsström and Vasemägi 2016). If larval detection is included in the eDNA definition, there are examples of the detection of larvae of an introduced Asterias species (Richardson et al. 2016) and for CoTS larvae using eDNA techniques (Uthicke et al. 2015a; Doyle et al. 2017).

This study is one of the first to apply eDNA techniques to quantify the abundance of a marine species over large scales $(>500 \mathrm{kms}$ ). Previous studies using single species detection on jellyfish (Minamoto et al. 2017) or Octopus (Mauvisseau 2017) focussed on kilometre scale patterns. Similarly, metabarcoding studies exploring diversity are often site specific and focusing on smaller geographic scales (Port et al. 2016; O'Donnell et al. 2017; Yamamoto et al. 2017).

Given sampling was not controlled for hydrographic factors such as currents or tide levels, CoTS density explained a surprisingly high amount of variance of eDNA concentrations. Samples taken at the depth of the density transects $\left(R^{2}=0.60\right)$ provided greater explanatory power than those from the sea surface $\left(R^{2}=0.46\right)$, potentially due to the surface water being at further distance from the benthic CoTS habitat and thus the actual eDNA source. In addition, surface samples (with the exception of Lizard Isl.) were taken at much lower replication than underwater samples. However, given surface samples are easier to obtain than underwater samples, collecting a larger number of surface samples at targeted locations and times may be the more cost effective method for monitoring. The proportion of positive samples explained a similar amount of variance as the average concentration, suggesting that both metrics are available for future monitoring.

Thus, after careful choice of sampling locations and times, based on reef scale hydrodynamics and biological considerations, our method is suitable for CoTS population monitoring and early detection of outbreaks. In cases where lower detection limits are required than reported here, for instance, for very early detection of primary outbreaks, the option for collecting larger water volumes at higher frequency and at more strategic locations and times is available. Thus, the methods developed may be an important supplement or replacement to traditional monitoring in the future. Development of automated samplers and possibly on board PCR in the future will further improve sampling and early detection. We propose that post-settlement monitoring in winter in combination with a targeted larval monitoring (Uthicke et al. 2015a; Doyle et al. 2017) in the summer spawning season provides the highest chance for early outbreak detection.
Acknowledgements We are grateful for the Association of Marine Park Tourism Operators ongoing support in field sampling. We would also like to extend our gratitude to the crew of the RV Cape Ferguson and staff of the Lizard Island Research Station. This research was supported through funding from the Australian Government's National Environmental Science Programme and AIMS appropriation funds. In addition, we received support from the Great Barrier Reef Marine Park Authority and two Grants from the Ian Potter Foundation. Aquarium testing of the methods has been conducted at the National Seas Simulator at AIMS (SeaSim).

\section{Compliance with ethical standards}

Conflict of interest The authors declare that they have no conflict of interest.

Open Access This article is distributed under the terms of the Creative Commons Attribution 4.0 International License (http://crea tivecommons.org/licenses/by/4.0/), which permits unrestricted use, distribution, and reproduction in any medium, provided you give appropriate credit to the original author(s) and the source, provide a link to the Creative Commons license, and indicate if changes were made.

\section{References}

Baird A, Pratchett M, Hoey A, Herdiana Y, Campbell S (2013) Acanthaster planci is a major cause of coral mortality in Indonesia. Coral Reefs:1-10

Birkeland C (1982) Terrestrial runoff as a cause of outbreaks of Acanthaster planci (Echinodermata: Asteroidea). Mar Biol 69:175-185

Black K, Moran P, Burrage D (1995) Association of low-frequency currents and crown-of-thorns starfish outbreaks. Mar Ecol Prog Ser 125:185-194

Brodie J, Fabricius K, De'ath G, Okaji K (2005) Are increased nutrient inputs responsible for more outbreaks of crown-ofthorns starfish? An appraisal of the evidence. Mar Pollut Bull 51:266-278

Bylemans J, Furlan EM, Gleeson DM, Hardy CM, Duncan RP (2018) Does size matter? An experimental evaluation of the relative abundance and decay rates of aquatic eDNA. Environmental Science \& Technology 52:6408-6416

Cowan Z-L, Pratchett M, Messmer V, Ling S (2017) Known predators of crown-of-thorns starfish (Acanthaster spp.) and their role in mitigating, if not preventing, population outbreaks. Diversity 9:7

De'ath G, Fabricius KE, Sweatman H, Puotinen M (2012) The 27-year decline of coral cover on the Great Barrier Reef and its causes. Proc Natl Acad Sci USA 9:17995-17999

Doyle JR, McKinnon AD, Uthicke S (2017) Quantifying larvae of the coralivorous seastar Acanthaster cf. solaris on the Great Barrier Reef using qPCR. Marine Biology 164:176

Fabricius KE, Okaji K, De'ath G (2010) Three lines of evidence to link outbreaks of the crown-of-thorns seastar Acanthaster planci to the release of larval food limitation. Coral Reefs 29:593-605

Fernandes L, Marsh H, Moran P, Sinclair D (1990) Bias in manta tow surveys of Acanthaster planci. Coral Reefs 9:155-160

Ficetola GF, Miaud C, Pompanon F, Taberlet P (2008) Species detection using environmental DNA from water samples. Biology letters 4:423-425

Forsström T, Vasemägi A (2016) Can environmental DNA (eDNA) be used for detection and monitoring of introduced crab species in the Baltic Sea? Marine Pollution Bulletin 109:350-355 
Fukumoto S, Ushimaru A, Minamoto T (2015) A basin-scale application of environmental DNA assessment for rare endemic species and closely related exotic species in rivers: a case study of giant salamanders in Japan. Journal of Applied Ecology 52:358-365

Hebert PD, Ratnasingham S, deWaard JR (2003) Barcoding animal life: cytochrome $\mathrm{c}$ oxidase subunit 1 divergences among closely related species. Proceedings Biological sciences/The Royal Society 270(Suppl 1):S96-99

Hindson BJ, Ness KD, Masquelier DA, Belgrader P, Heredia NJ, Makarewicz AJ, Bright IJ, Lucero MY, Hiddessen AL, Legler TC (2011) High-throughput droplet digital PCR system for absolute quantitation of DNA copy number. Analytical chemistry 83:8604-8610

Hughes TP, Kerry JT, Álvarez-Noriega M, Álvarez-Romero JG, Anderson KD, Baird AH, Babcock RC, Beger M, Bellwood DR, Berkelmans R, Bridge TC, Butler IR, Byrne M, Cantin NE, Comeau S, Connolly SR, Cumming GS, Dalton SJ, Diaz-Pulido G, Eakin CM, Figueira WF, Gilmour JP, Harrison HB, Heron SF, Hoey AS, Hobbs J-PA, Hoogenboom MO, Kennedy EV, C-y Kuo, Lough JM, Lowe RJ, Liu G, McCulloch MT, Malcolm HA, McWilliam MJ, Pandolfi JM, Pears RJ, Pratchett MS, Schoepf V, Simpson T, Skirving WJ, Sommer B, Torda G, Wachenfeld DR, Willis BL, Wilson SK (2017) Global warming and recurrent mass bleaching of corals. Nature 543:373-377

Hunter ME, Dorazio RM, Butterfield JS, Meigs-Friend G, Nico LG, Ferrante JA (2017) Detection limits of quantitative and digital PCR assays and their influence in presence-absence surveys of environmental DNA. Molecular ecology resources 17:221-229

Jerde CL, Chadderton WL, Mahon AR, Renshaw MA, Corush J, Budny ML, Mysorekar S, Lodge DM (2013) Detection of Asian carp DNA as part of a Great Lakes basin-wide surveillance program. Canadian Journal of Fisheries and Aquatic Sciences 70:522-526

Kayal M, Vercelloni J, Lison de Loma T, Bosserelle P, Chancerelle Y, Geoffroy S, Stievenart C, Michonneau F, Penin L, Planes S, Adjeroud M (2012) Predator crown-of-thorns starfish (Acanthaster planci) outbreak, mass mortality of corals, and cascading effects on reef fish and benthic communities. PLoS ONE 7:e47363

Kelly RP, Port JA, Yamahara KM, Crowder LB (2014) Using environmental DNA to census marine fishes in a large mesocosm. PloS one 9:e86175

Klymus KE, Richter CA, Chapman DC, Paukert C (2015) Quantification of eDNA shedding rates from invasive bighead carp Hypophthalmichthys nobilis and silver carp Hypophthalmichthys molitrix. Biological Conservation 183:77-84

Maruyama A, Nakamura K, Yamanaka H, Kondoh M, Minamoto T (2014) The release rate of environmental DNA from juvenile and adult fish. PLoS One 9:e114639

Mauvisseau Q (2017) On the way for detecting and quantifying elusive species in the sea: The Octopus vulgaris case study. Fisheries research 191:41-48

Minamoto T, Naka T, Moji K, Maruyama A (2016) Techniques for the practical collection of environmental DNA: filter selection, preservation, and extraction. Limnology 17:23-32

Minamoto T, Fukuda M, Katsuhara KR, Fujiwara A, Hidaka S, Yamamoto S, Takahashi K, Masuda R (2017) Environmental DNA reflects spatial and temporal jellyfish distribution. PloS one 12:e0173073

Nakamura M, Okaji K, Higa Y, Yamakawa E, Mitarai S (2014) Spatial and temporal population dynamics of the crown-ofthorns starfish, Acanthaster planci, over a 24-year period along the central west coast of Okinawa Island, Japan. Marine biology $161: 2521-2530$
O’Donnell JL, Kelly RP, Shelton AO, Samhouri JF, Lowell NC, Williams GD (2017) Spatial distribution of environmental DNA in a nearshore marine habitat. PeerJ 5:e3044

Port JA, O'Donnell JL, Romero-Maraccini OC, Leary PR, Litvin SY, Nickols KJ, Yamahara KM, Kelly RP (2016) Assessing vertebrate biodiversity in a kelp forest ecosystem using environmental DNA. Molecular ecology 25:527-541

Pratchett M, Caballes CF, Rivera-Posada J, Sweatman H (2014) Limits to understanding and managing outbreaks of crown-ofthorns starfish (Acanthaster spp.). Oceanogr Mar Biol Ann Rev 52:133-200

Pratchett M, Caballes C, Wilmes J, Matthews S, Mellin C, Sweatman H, Nadler L, Brodie J, Thompson C, Hoey J, Bos A, Byrne M, Messmer V, Fortunato S, Chen C, Buck A, Babcock R, Uthicke S (2017) Thirty years of research on crown-of-thorns starfish (1986-2016): Scientific advances and emerging opportunities. Diversity 9:41

Rees HC, Maddison BC, Middleditch DJ, Patmore JR, Gough KC (2014) The detection of aquatic animal species using environmental DNA-a review of eDNA as a survey tool in ecology. Journal of Applied Ecology 51:1450-1459

Richardson MF, Sherman CD, Lee RS, Bott NJ, Hirst AJ (2016) Multiple dispersal vectors drive range expansion in an invasive marine species. Molecular Ecology 25:5001-5014

Sigsgaard EE, Nielsen IB, Bach SS, Lorenzen ED, Robinson DP, Knudsen SW, Pedersen MW, Al Jaidah M, Orlando L, Willerslev E (2016) Population characteristics of a large whale shark aggregation inferred from seawater environmental DNA. Nature Ecology \& Evolution 1:0004

Spens J, Evans AR, Halfmaerten D, Knudsen SW, Sengupta ME, Mak SS, Sigsgaard EE, Hellström M (2017) Comparison of capture and storage methods for aqueous macrobial eDNA using an optimized extraction protocol: advantage of enclosed filter. Methods in Ecology and Evolution 8:635-645

Stat M, Huggett MJ, Bernasconi R, DiBattista JD, Berry TE, Newman SJ, Harvey ES, Bunce M (2017) Ecosystem biomonitoring with eDNA: metabarcoding across the tree of life in a tropical marine environment. Scientific Reports 7:12240

Thomsen PF, Willerslev E (2015) Environmental DNA-An emerging tool in conservation for monitoring past and present biodiversity. Biological Conservation 183:4-18

Thomsen PF, Kielgast J, Iversen LL, Møller PR, Rasmussen M, Willerslev E (2012) Detection of a diverse marine fish fauna using environmental DNA from seawater samples. PLoS ONE 7:e41732

Turner CR, Barnes MA, Xu CC, Jones SE, Jerde CL, Lodge DM (2014) Particle size distribution and optimal capture of aqueous macrobial eDNA. Methods in Ecology and Evolution 5:676-684

Uthicke S, Schaffelke B, Byrne M (2009) A boom-bust phylum? Ecological and evolutionary consequences of density variations in echinoderms. Ecol Monogr 79:3-24

Uthicke S, Byrne M, Conand C (2010) Genetic barcoding of commercial Beche-de-mer species (Echinodermata: Holothuroidea). Mol Ecol Resour 10:634-646

Uthicke S, Doyle J, Duggan S, Yasuda N, McKinnon AD (2015a) Outbreak of coral-eating Crown-of-Thorns creates continuous cloud of larvae over $320 \mathrm{~km}$ of the Great Barrier Reef. Scientific Reports 5:16885

Uthicke S, Logan M, Liddy M, Francis D, Hardy N, Lamare M (2015b) Climate change as an unexpected co-factor promoting coral eating seastar (Acanthaster planci) outbreaks. Scientific Reports 5:8402

Uthicke S, Liddy M, Patel F, Logan M, Johansson C, Lamare M (2018) Effects of larvae density and food concentration on Crown-of-Thorns seastar (Acanthaster cf. solaris) development in an automated flow-through system. Scientific reports 8:642 
Vanhatalo J, Hosack GR, Sweatman H (2017) Spatio-temporal modelling of crown-of-thorns starfish outbreaks on the Great Barrier Reef to inform control strategies. Journal of Applied Ecology 54:188-197

Vogler AP, Monaghan MT (2007) Recent advances in DNA taxonomy. Journal of Zoological Systematics and Evolutionary Research 45:1-10

Ward RD, Holmes BH, O'Hara TD (2008) DNA barcoding discriminates echinoderm species. Mol Ecol Resour 8:1202-1211

Wooldridge SA, Brodie JE (2015) Environmental triggers for primary outbreaks of crown-of-thorns starfish on the Great Barrier Reef, Australia. Mar Pollut Bull 101:805-815

Yamahara KM, Demir-Hilton E, Preston CM, Marin R 3rd, Pargett D, Roman B, Jensen S, Birch JM, Boehm AB, Scholin CA (2015) Simultaneous monitoring of faecal indicators and harmful algae using an in situ autonomous sensor. Letters in applied microbiology 61:130-138

Yamamoto S, Masuda R, Sato Y, Sado T, Araki H, Kondoh M, Minamoto T, Miya M (2017) Environmental DNA metabarcoding reveals local fish communities in a species-rich coastal sea. Scientific reports 7:40368

Yamamoto S, Minami K, Fukaya K, Takahashi K, Sawada H, Murakami H, Tsuji S, Hashizume H, Kubonaga S, Horiuchi T, Hongo M, Nishida J, Okugawa Y, Fujiwara A, Fukuda M, Hidaka S, Suzuki KW, Miya M, Araki H, Yamanaka H, Maruyama A, Miyashita K, Masuda R, Minamoto T, Kondoh M (2016) Environmental DNA as a 'Snapshot' of Fish Distribution: A Case Study of Japanese Jack Mackerel in Maizuru Bay, Sea of Japan. PLOS ONE 11:e149786 